\title{
Performance of OLTC-based control strategies for LV networks with photovoltaics
}

DOI:

10.1109/PESGM.2015.7285618

Link to publication record in Manchester Research Explorer

\section{Citation for published version (APA):}

Long, C., Procopiou, A. T., Ochoa, L. F., Bryson, G., \& Randles, D. (2015). Performance of OLTC-based control strategies for LV networks with photovoltaics. In IEEE/PES General Meeting 2015 (pp. 1-5)

https://doi.org/10.1109/PESGM.2015.7285618

\section{Published in:}

IEEE/PES General Meeting 2015

\section{Citing this paper}

Please note that where the full-text provided on Manchester Research Explorer is the Author Accepted Manuscript or Proof version this may differ from the final Published version. If citing, it is advised that you check and use the publisher's definitive version.

\section{General rights}

Copyright and moral rights for the publications made accessible in the Research Explorer are retained by the authors and/or other copyright owners and it is a condition of accessing publications that users recognise and abide by the legal requirements associated with these rights.

\section{Takedown policy}

If you believe that this document breaches copyright please refer to the University of Manchester's Takedown Procedures [http://man.ac.uk/04Y6Bo] or contact uml.scholarlycommunications@manchester.ac.uk providing relevant details, so we can investigate your claim.

\section{OPEN ACCESS}




\section{Performance of OLTC-Based Control Strategies for LV Networks with Photovoltaics}

\author{
Chao Long, Andreas T. Procopiou, Luis F. Ochoa \\ The University of Manchester \\ Manchester, UK \\ chao.long.10@gmail.com; \\ andreas.procopiou@manchester.ac.uk; luis_ochoa@ieee.org
}

\author{
Geraldine Bryson, Dan Randles \\ Electricity North West Ltd \\ Warrington, UK \\ geraldine.bryson@enwl.co.uk; dan.randles@enwl.co.uk
}

\begin{abstract}
The adoption of on-load tap changer (OLTC)-fitted transformers in low voltage (LV) networks is increasingly being considered to mitigate voltage issues resulting from high penetrations of photovoltaic (PV) systems. However, depending on the corresponding voltage control strategy, tap operations can be significant, accelerating the ageing of the OLTC. This work assesses the performance of different OLTC control strategies: constant set-point, time-based and remote monitoring-based. A Monte Carlo-based time-series analysis is used considering different PV penetrations. A real UK residential $L V$ network is analyzed using the number of tap operations and voltage compliance with the standard BS EN50160 as key performance metrics throughout a week. Results show that remote monitoring-based control can significantly enhance the network's ability to host PV systems whilst limiting tap operations and voltage issues. The results are expected to help distribution network operators determine the most adequate control strategy for OLTC-fitted transformers in future $\mathrm{LV}$ networks.
\end{abstract}

Index Terms--Distribution network, low voltage, on-load tap changer, photovoltaic, voltage control

\section{INTRODUCTION}

Solar photovoltaic (PV) technologies are one of the fastest growing renewable energy sources being integrated worldwide onto the electrical distribution systems. Smallscale PV systems are expected to reach higher penetration levels over the next decades but are already leading to technical challenges in areas where cluster exists. Voltage violation is one of the dominant constraints that limit the ability of low voltage (LV) distribution networks to host large penetrations of PV systems.

In the UK and in most countries in the world, LV networks are typically equipped with off-load tap changers which means that the fine tuning of the ratio between the primary and secondary of the transformers can only be changed when disconnecting the load. To extend the 'on load' flexibility in terms of voltage management closer to the LV customers, the use of on-load tap changer (OLTC)-fitted distribution transformers has been recently studied particularly in the context of residential scale PV systems [1]-
[3]. However, depending on the corresponding voltage control strategy, tap operations can be significant, leading to the wear and tear of the OLTC [4]. Therefore, an adequate OLTC control strategy should be used to ensure customer voltages are within statutory limits whilst minimizing tap operations so as to reduce the maintenance/overhaul cost incurred by the distribution network operator (DNO).

Most of the studies found in the literature focus on control strategies that integrate the operation of LV OLTC-fitted transformers and other controllable elements. The technical and economic benefits of controlling active and reactive power of residential-scale PV as well as OLTC were assessed in [1]. This, however, was limited to only a few snapshots of demand and generation rather than a time-series analysis. In terms of impacts, only the voltage at the 'weakest' point was quantified rather than considering voltages at all customer connection points. The number of tap operations was not quantified. In [2], a sensitivity-based coordinated control of battery-based energy storage system and OLTC was proposed to increase the network's ability to host low carbon technologies. The effects on tap operations were quantified but the adopted time-series analysis was limited to six hours. These two studies did not provide a clear quantification of the benefits from the sole use of the OLTC and the different strategies that could be adopted to control voltages over significant periods of time.

The performance of an LV OLTC-fitted transformer was analyzed in [3] considering a load-based control algorithm. The OLTC set-point was changed depending on the total load variation. This method, however, requires the impedances of the feeders to approximate suitable set-points. Consequently, the algorithm needs to be tuned for each network where it will be deployed making it less practical.

It is important to highlight that the above studies were carried out considering deterministic approaches, i.e., neglecting the uncertainties involved in the residential PV generation as well as domestic demand. To adequately quantify the performance of a given LV OLTC control strategy, the uncertainties surrounding the characteristics of the PV generation and demand (i.e., location, size, and 
variability) need to be catered for. In addition, the particular characteristics of UK LV networks (i.e., three-phase fourwire feeders with single-phase connected loads), as well as detailed operational aspects of the OLTC such as bandwidth and control cycles have also to be modelled.

In this paper, three OLTC control strategies, constant setpoint control (CSC), time-based control (TC) and remote monitoring-based control (RMC), are applied to a real UK LV network. A Monte Carlo methodology previously developed in [5], [6] considering 1-minute resolution is carried out throughout a week to assess the control performances using the number of tap operations and voltage compliance with the British Standard BS EN50160 as key metrics. The results of this work are expected to help DNOs determine the most adequate control strategy for OLTC-fitted transformers in future LV networks.

\section{NETWORK MODELLING}

\section{A. Real UK LV Distribution Network}

To implement the proposed methodology, a real LV residential distribution network located in the North West of England is used. The $11 \mathrm{kV} / 400 \mathrm{~V}$ network is comprised of six radial feeders (three-phase four-wire underground cables). The rated capacity of the distribution transformer is $500 \mathrm{kVA}$. The topology of the network is shown in Fig. 1, where the triangle represents the transformer. Different feeders are shown in different colours and each solid dot represents a house/customer. There are 49, 21, 30, 100, 68 and 83 customers, respectively, in the six feeders (i.e., 351 in total), all with single-phase connections. The black rectangles at the mid and end points of the feeders correspond to feasible locations for remote monitoring devices.

The voltage limits in UK LV networks are $+10 /-6 \%$ of nominal, i.e., $253 \mathrm{~V}$ (1.10 p.u.) and $216 \mathrm{~V}$ (0.94 p.u.) line-toneutral. Compliance with these limits is checked according to the BS EN50160 standard [7], by which 95\% of voltages (10min average rms values) within a week must be between 1.10 and 0.90 p.u., and never outside 1.10 and 0.85 p.u.

\section{B. Load and Photovoltaic Profiles}

The tool developed by the Centre for Renewable Energy Systems Technology (CREST) [8] is used for modelling the domestic load profiles given its high time-granularity (one minute). The load of each individual household is modelled realistically considering type of day, seasonality, occupancy and the associated use of electrical appliances [8].

For each feeder of the network, the adopted number of occupants per household follows UK statistics [9], i.e., the percentage of houses with 1, 2, 3 and more than 4 persons are $29,35,16$ and $20 \%$, respectively. Once the number of occupants per house is randomly determined, the load profiles are created adopting a particular day of the year. For the PV systems, the corresponding generation for the same day is produced also using the CREST tool. The nominal capacity of the PV systems is randomly selected from a range of 2.0 to $3.5 \mathrm{kWp}$. Fig. 2 shows the daily (weekday, July) profile of the electricity consumption of a house with 2 occupants and the PV generation profile for the same day. The corresponding net electricity demand is also presented.

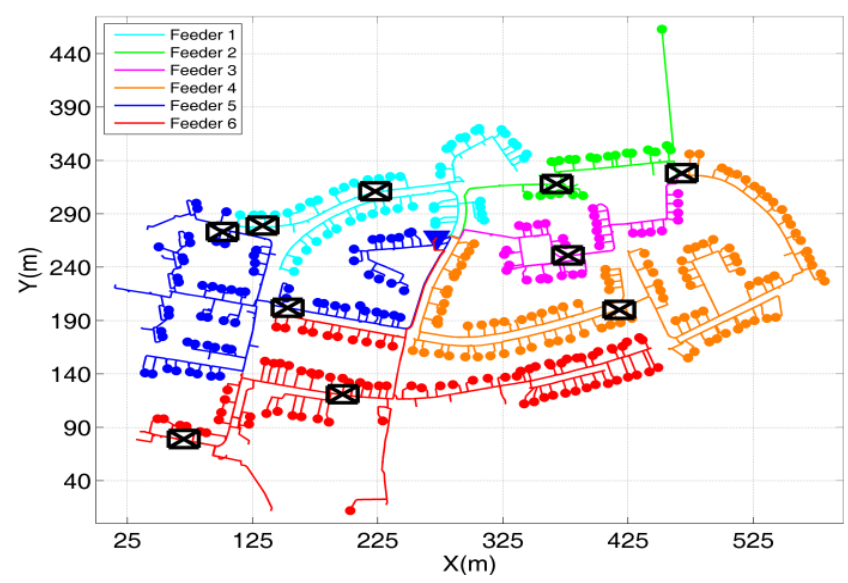

Figure 1. Real UK LV distribution network

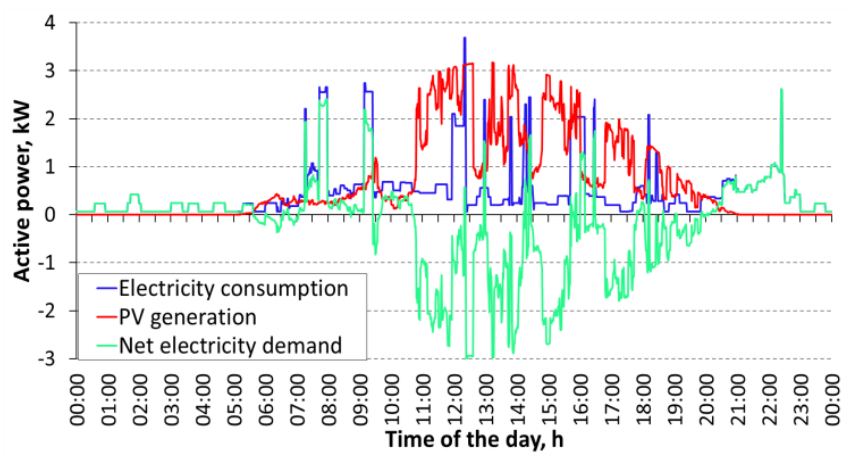

Figure 2. Daily (weekday, July) electricity consumption and PV generation profiles for a house with 2 occupants

\section{Distribution Transformer and OLTC}

In the UK, the distribution transformer ratio is typically $11 \mathrm{kV}$ (or $6.6 \mathrm{kV}$ ) to $433 \mathrm{~V}$. The off-load tap changer capability range is $\pm 5 \%$ (5 tap positions, $2.5 \%$ per step) and is commonly set to the nominal tap position $(\sim 250 \mathrm{~V} \mathrm{~L}-\mathrm{N})$. The OLTC studied in this work has a range of $\pm 8 \%$ with $2 \%$ per tap, i.e., 9 tap positions in total. Assuming that the voltage at the primary of the transformer is the nominal (i.e., $11 \mathrm{kV}$ lineto-line), the line-to-neutral voltages at the busbar will be $231.5,235.8,240.4,245.1,250.0,255.1,260.4,265.9$ and 271.7V corresponding to the tap positions from 1 to 9 .

\section{OLTC-BASED CONTROL STRATEGIES}

In this section, first the basic OLTC control concepts are presented. Then, three control strategies are investigated to maximize the benefits brought by OLTC-fitted transformers.

\section{A. Basic OLTC Control Concepts}

The OLTC keeps the secondary bus (busbar) voltage within a bandwidth, as shown in (1).

$$
V_{L B} \leq V_{\text {busbar }} \leq V_{U B}
$$

where, $V_{\text {busbar }}$ is the transformer secondary bus (busbar) voltage; $V_{L B}$ is the lower boundary voltage $\left(V_{\text {set }}-0.5 B W\right)$; $V_{U B}$ is the upper boundary voltage $\left(V_{\text {set }}+0.5 B W\right) ; V_{\text {set }}$ is the set-point voltage; and, $B W$ is the bandwidth. 
Once the set-point voltage and bandwidth are set, the OLTC will adjust its tap position accordingly. The busbar voltage is checked frequently (e.g., 1 second). However, the actual tap change occurs if the bandwidth has been exceeded for longer than a pre-defined delay (e.g., 2 minutes).

Assuming that the magnitude of the voltage change at the busbar for a single tap operation (one step) is $V_{\text {one-tap }}$, the chosen bandwidth has to be larger, as shown in (2).

$$
B W>V_{\text {one-tap }}
$$

\section{B. Constant Set-point Control (CSC)}

The principle for this control strategy is that the set-point voltage keeps a fixed value all the time. There will still be tap operations as the OLTC will change the position to maintain the busbar voltage at, or close to, the set-point voltage. For this control strategy, $240.2 \mathrm{~V}$ line-to-neutral, i.e., 1.04 p.u., was taken as the set-point voltage. This value provides extra headroom for PV generation compared to the business as usual approach ( $250 \mathrm{~V}$ using the off-load tap changer) whilst coping with potential voltage drops during peak demand.

\section{Time-based Control (TC)}

In the UK, voltage rise due to PV systems happens because of its coincidence with minimum demand. This PV generation does not extend considerably to hours of peak demand (e.g., 17:00 to 20:00). Hence, by changing the setpoint voltage according to the time it is possible to adopt a less conservative value during minimum demand and a more conservative one during peak. The set-point voltages for different periods of the day adopted for the TC strategy are shown in Table I.

\section{Remote Monitoring-based Control (RMC)}

\section{1) Architecture}

A schematic of the proposed control architecture is shown in Fig. 3. Three feeders are shown for illustration purposes. The remote voltage monitoring devices are installed at the mid and end points of the LV feeders. These devices send the voltages to a remote terminal unit (RTU) located at the substation. In this case, the RTU is a physical device in which the control logic is coded. Based on this logic, the RTU then sends to the tap changer controller a command to produce a set-point voltage that ultimately alleviates any potential issue.

\section{2) Control Logic}

For the RMC, the set-point voltage is changed according to the measured voltages at the busbar as well as mid and end points. Consequently, if needed, this set-point is changed as frequently as the control cycles.

Considering the busbar voltage as a reference, a compensating voltage $\left(\Delta V_{i}\right)$ for the control cycle $i$ is calculated taking into account the monitoring voltages. The new set-point voltage $\left(V_{\text {set } i+1}\right)$ is then obtained by the difference between the monitoring busbar voltage ( $V_{\text {busbar }}$, average of the control cycle) and the compensating voltage $\left(\Delta V_{i}\right)$, as shown in (3). This process takes place every control cycle (e.g., every 5 minutes, every 15 minutes, etc.).

$$
V_{\text {set } i+1}=V_{\text {busbar } i}-\Delta V_{i}
$$

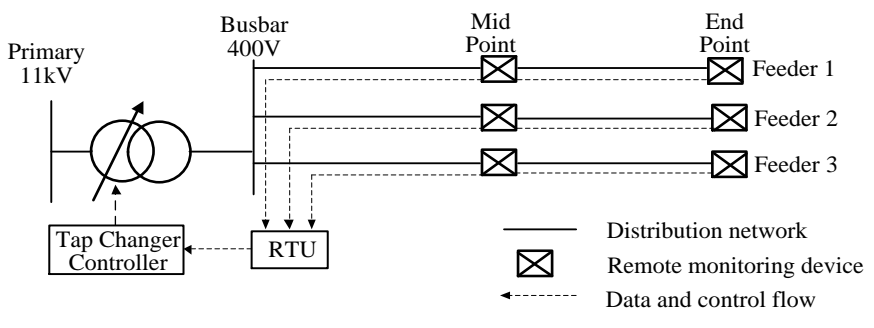

Figure 3. Remote monitoring-based control architecture

TABLE I. SET-POINT VOLTAGES FOR DIFFERENT PERIODS OF THE DAY

\begin{tabular}{cc}
\hline \hline Time & Set-point Voltage \\
\hline 6:00 to $16: 59$ & $237.9 \mathrm{~V}(1.03$ p.u. $)$ \\
\hline 00:00 to 5:59 and 17:00 to $23: 59$ & $242.5 \mathrm{~V}$ (1.05 p.u.) \\
\hline \hline
\end{tabular}

\begin{tabular}{|c|c|c|c|c|c|}
\hline & \multicolumn{5}{|c|}{ Maximum } \\
\hline & Red & Orange & $\begin{array}{c}\text { Green } \\
48 \mathrm{~V}>>? 1 \mathrm{~V}\end{array}$ & Orange & Red \\
\hline$>253 \mathrm{~V}$ & +3 & & & & \\
\hline Orange $253 \mathrm{~V} \geq \geq 248 \mathrm{~V}$ & +2 & +2 & & & \\
\hline$\underline{E}$ Green $248 \mathrm{~V}>\geq 221 \mathrm{~V}$ & +2 & +1 & 0 & & \\
\hline Orange $221 \mathrm{~V}>. \geq 216 \mathrm{~V}$ & +1 & 0 & -1 & -2 & \\
\hline$<216 \mathrm{~V}$ & 0 & -1 & -2 & -2 & -3 \\
\hline
\end{tabular}

TABLE II. COMPENSATING Voltage FACTOR IN Voltage Zones

To calculate the compensating voltage, three voltage zones have been defined as presented in Table II. If voltages at the mid and end points breach the statutory limits, i.e., either higher than $253 \mathrm{~V}$ or lower than $216 \mathrm{~V}$, they are in the red zone. When voltages are up to $2 \%$ close to the boundary, i.e., from 248 to $253 \mathrm{~V}$ and from 216 to $221 \mathrm{~V}$, then they are considered to be in the orange zone. Finally, voltages between 221 and $248 \mathrm{~V}$ correspond to the green zone.

By determining how far the monitoring voltages, in particular the maximum and minimum values, are from the ideal range (i.e., the green zone) it is possible to estimate the needed compensation at the busbar voltage. The latter, however, has to be estimated considering the tap steps that the OLTC might require. This estimation is presented in Table II where each value corresponds to a factor that should be multiplied by $V_{\text {one-tap }}$.

Therefore, for a given control cycle $i$, first the voltage zones of the maximum and minimum of all the mid and end point voltages are determined. The compensating voltage $\left(\Delta V_{i}\right)$ is then obtained by multiplying the corresponding factor in Table II and $V_{\text {one-tap }}$ equal to $4.6 \mathrm{~V}$ (2\% tap step).

\section{CASE STUdy}

In this section, the control strategies CSC, TS, and RMC are applied to the LV network presented in section II. The distribution system analysis software package OpenDSS [10] and MATLAB are used to run time-series power flow simulations and the corresponding control strategies.

Different PV penetrations (from 0 to $70 \%$ ) are studied. In this paper, the PV penetration is calculated by the number of houses having PV systems in relation to the total number of houses. For a certain penetration, PV systems are randomly allocated assuming all feeders have the same penetration 


\section{Accepted Paper}

level. Due to the area of LV networks, for a given day, all PV systems are considered to have the same generation profile. The aggregated daily load profiles of the network with 0,30 , and $70 \% \mathrm{PV}$ penetrations are illustrated in Fig. 4. $70 \%$ was considered as the highest PV penetration as the peak reverse power reaches the transformer rating.

For comparison purposes, the network equipped with offload tap changer is also analyzed considering a suitable tap position to cope with PV systems $(+2.5 \%$, i.e., $244 \mathrm{~V})$.

\section{A. Deterministic Analysis}

The three-phase power flow simulations are carried out on a weekly basis. Fig. 5, Fig. 6, and Fig. 7 show the profiles for a week in July (summer) with a $70 \%$ PV penetration for the CSC, TC and RMC strategies, respectively. The set-point voltage, the corresponding tap position and the busbar voltage profiles are plotted in part (a) of these figures. Voltages for the far end customers in the 6 feeders are illustrated in part (b). The bandwidth used in all simulations was $2.2 \%$.

For the RMC, 5, 15 and 30-min control cycles are investigated in this paper. 5-min is considered as the shortest control cycle so as to cater for the communication and tap operation delay times. Detailed results for the 30-min control cycle are presented in Fig. 7.

For the studied summer week, the CSC, TC and RMC strategies resulted in $8.3,7.7$ and $5.4 \%$ of the 351 customers non-compliant with BS EN50160 voltages. This shows a clear improvement when adopting the remote control, particularly in comparison with the off-load tap changer $(41.5 \%)$. In terms of the usage of the OLTC, for this week each of the control strategies required 114, 80 and 19 tap changes, respectively. In this case, the RMC resulted in just a fraction of the tap changes needed by other two strategies.

\section{B. Monte Carlo Analysis}

Fifty simulations each representing a week in July (summer) are carried out to extend the potential diversity in PV generation and household demand. The average and standard deviation of the percentage of non-compliant customers for different control strategies are shown in Fig. 8. The daily average number of tap changes and the corresponding standard deviation are shown in Fig. 9.

As seen in Fig. 8, with the off-load tap changer customers present voltage issues from $20 \% \mathrm{PV}$ penetration. With a $70 \%$ penetration, nearly $50 \%$ customers are non-compliant with BS EN50160. On the other hand, with the OLTC, disregarding the control strategy, it is only until $40 \%$ of PV penetration that customers might experience voltage problems. The three control cycles $(5,15$ and 30-min) studied for the RMC strategy outperformed the CSC and TC in terms of voltages. The RMC also resulted in the fewest tap operations in all PV penetrations. Interestingly, although the TC has a better performance than CSC in terms of voltages, this is mostly done at the expense of more tap operations.

\section{Monte Carlo Analysis vs Deterministic Analysis}

For the deterministic analysis, the results are limited to the specific week and therefore cannot be generalized. For example, due to the uncertainties of PV generation and

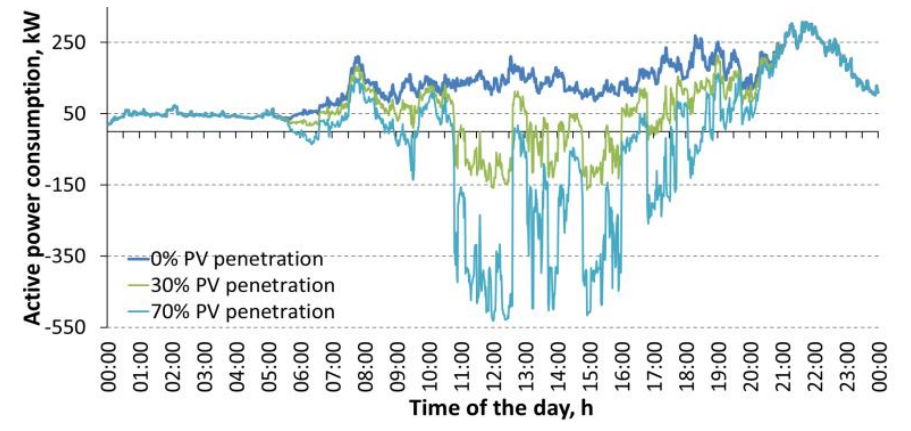

Figure 4. The aggregated daily load profiles of the network

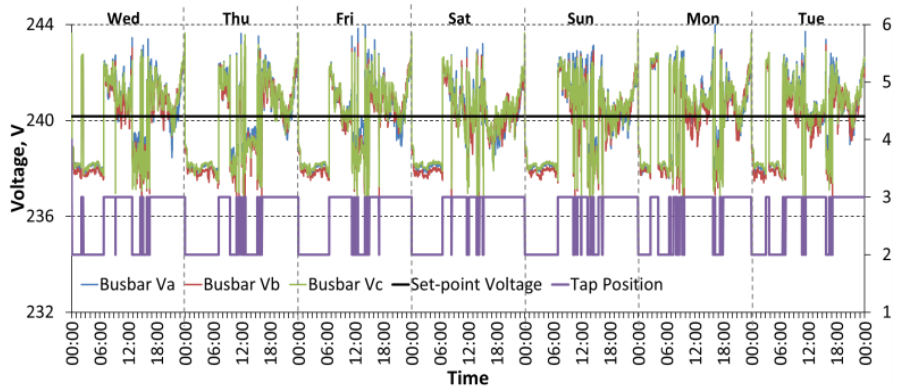

(a) busbar voltage and tap position

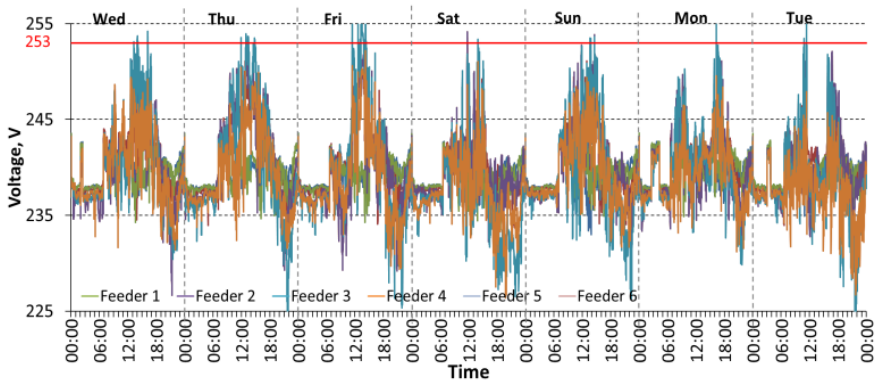

(b) far end customer voltage

Figure 5. One-week (July) voltage profiles by CSC

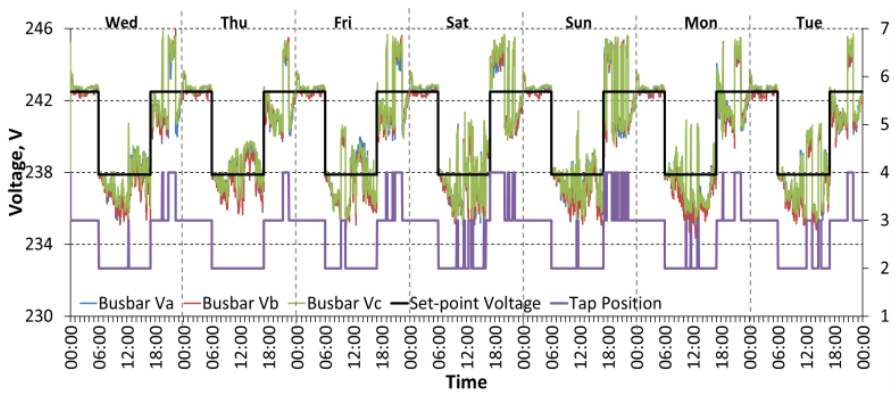

(a) busbar voltage and tap position

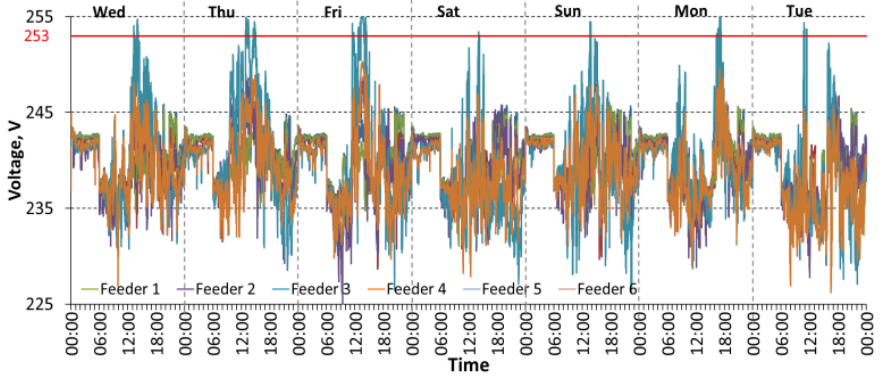

(b) far end customers

Figure 6. One-week (July) voltage profiles by TC 


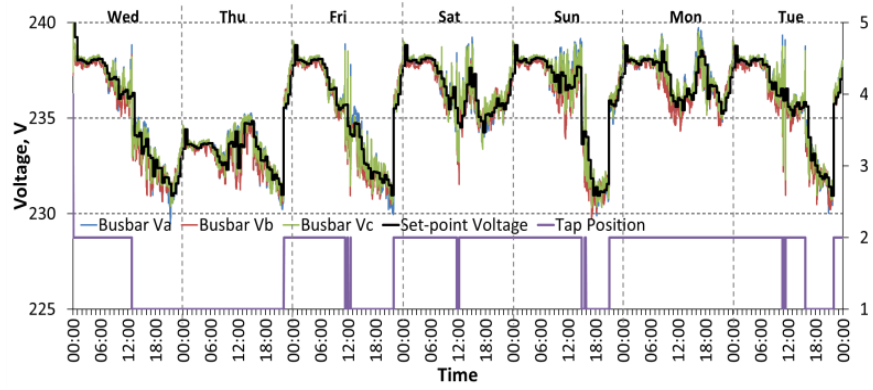

(a) busbar voltage and tap position

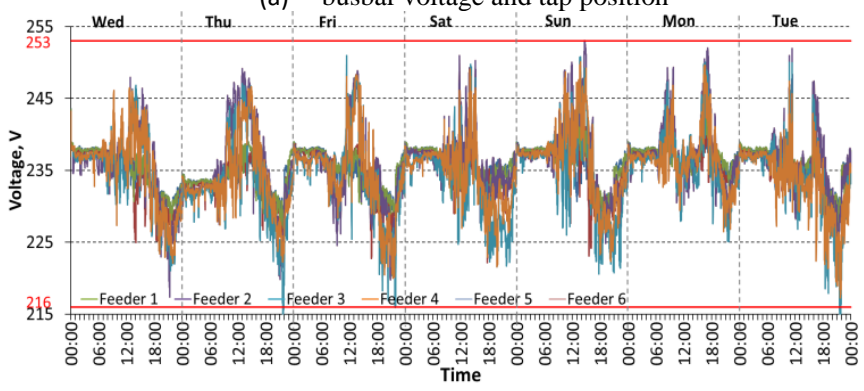

(b) far end customers

Figure 7. One-week (July) voltage profiles by RMC, 30-min control cycle

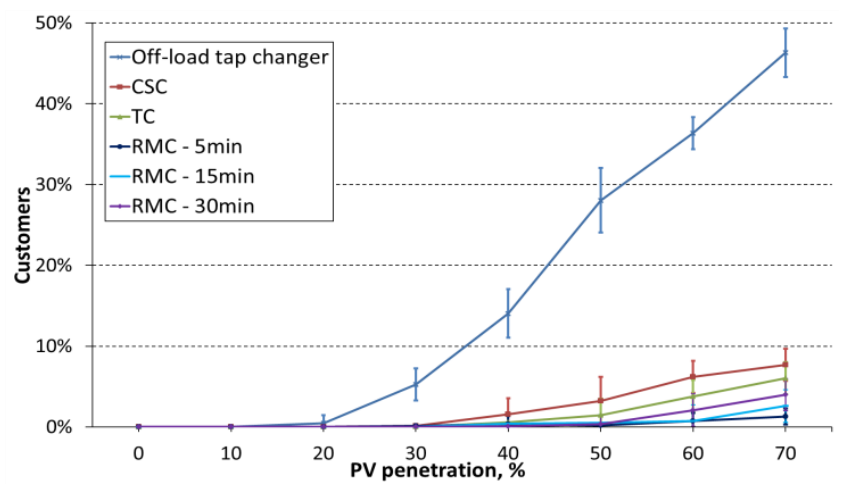

Figure 8. Customers with voltage problems - comparison

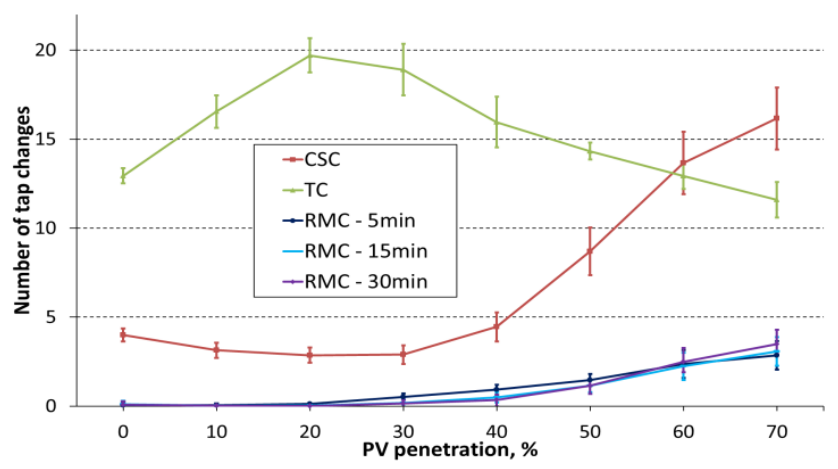

Figure 9. Daily average number of tap changes - comparison

demand, results could be different in another simulated week. These uncertainties, however, are catered for when adopting the Monte Carlo analysis. Due to the multiple simulations (fifty) carried out, the average and standard deviations are obtained as a way to generalize the results. This can show not only the number of non-compliant customers and the tap changes, but also the likelihood of these values. Therefore, by using the Monte Carlo analysis it is possible to show a much more general picture of the metrics of interest.

\section{DISCUSSION}

A bandwidth of $2.2 \%$ was used in all simulations in this work. Different bandwidths may result in different voltage profiles and different number of tap changes. However, the trends found for the control strategies investigated here are expected to be similar for other bandwidths.

This work only focused on the 'worst-case' season for the UK, i.e., the summer. To better assess the control strategies throughout the potential demand and generation changes in a year, other seasons should be investigated.

The same PV penetration is considered among all of the 6 feeders in all simulations. However, in practice, different feeders may have different PV penetrations. Dissimilar penetrations per feeders should be considered.

\section{CONCLUSIONS}

Three proposed OLTC control strategies are applied to a real UK LV distribution network to assess the benefits brought by OLTC-fitted transformers. A Monte Carlo approach is adopted to cater for the uncertainties surrounding domestic-scale PV generation and demand. The results show that the remote monitoring-based control can significantly enhance the network's ability to host PV systems whilst limiting tap operations and voltage issues. Nonetheless, the time-based control resulted in a comparable performance in terms of voltages and hence can be considered as a potential solution without the need of remote monitoring - although at the expense of more tap operations.

\section{ACKNOWLEDGEMENT}

The authors would like to thank Electricity North West Limited (ENWL), UK for the data provided for this work.

\section{REFERENCES}

[1] T. Stetz et al., "Improved low voltage grid-integration of photovoltaic systems in Germany," IEEE Trans Sustainable Energy, vol. 4, no. 2, pp. 534-542, Apr. 2013.

[2] P. Wang et al., "Integrating electrical energy storage into coordinated voltage control schemes for distribution networks," IEEE Trans Smart Grid, vol. 5, no. 2, pp. 1018-1032, Mar. 2014.

[3] C. Körner et al., "Gaining experience with a regulated distribution transformer in a smart grid environment," in CIRED Workshop, Lisbon, Portugal, May 2012, pp. 1-4.

[4] Y. P. Agalgaonkar, et al., "Distribution voltage control considering the impact of PV generation on tap changers and autonomous regulators, " IEEE Trans Power Syst., vol. 29, no. 1, pp. 182-192, Jan. 2014.

[5] A. Navarro et al., "Monte Carlo-based assessment of PV Impacts on real UK low voltage networks," in Proc. 2013 IEEE/PES General Meeting, Jul. 2013, pp. 1-5.

[6] A. Navarro and L. F. Ochoa, "What-if scenario Impact studies based on real LV networks," LV network solutions, 9th Sep. 2014.

[7] Voltage characteristics of electricity supplied by public electricity networks, BS EN50160, 2010.

[8] I. Richardson et al., "Domestic electricity use: a high-resolution energy demand model," Energy and Buildings, vol. 42, no. 10, pp.1878-1887, Oct. 2010.

[9] Office for National Statistics. (2013, Nov. 22). Statistical Bulletin: Families and Households, 2013, [Online]. Available: http://www.ons.gov.uk/ons/dcp171778_332633.pdf.

[10] R. C. Dugan and T. E. McDermott, "An open source platform for collaborating on smart grid research," IEEE Power and Energy Society General Meeting, pp. 1-7, Jul. 2011. 